\title{
Precocious Puberty in a Three Year Old Boy: A Hormone Secreting Testicular Tumor Should be High in Differential Diagnosis
}

\author{
Kailas Bhandarkar P, Dinesh H Kittur, Santosh V Patil, Sudhakar S Jadhav \\ Department of Pediatric Surgery, Sushrut Jadav Kinderchirurgie Charitable Trust's Pediatric Surgery Centre and PG Institute, \\ Sangli, Maharastra-416415, India.
}

\section{Corresponding Author:}

Dr. Kailas Bhandarkar P

Email: drbhandarkar@hotmail.com

This is an Open Access article distributed under the terms of the Creative Commons Attribution License (creativecommons.org/ licenses/by/3.0).

Received

Accepted

Published

June 11, 2017

August 30, 2017

October 15, 2017

\begin{abstract}
Background: Etiologies of iso-sexual precocious puberty are numerous. Among common causes for precocious puberty, hormone secreting testicular tumors are important. Leydig cell tumor is a sex cord stromal tumor of the testis. This usually presents with precocious puberty in pre-adolescent boys. Case Report: Our patient is a three year old boy who presented to his pediatrician with one year history of iso-sexual precocious puberty. Later, a right testicular mass was detected. He underwent an inguinal orchidectomy. Conclusion: Hormone secreting testicular tumors should be always be high in differential diagnosis in boys who present with precocious puberty and testicular enlargement.
\end{abstract}

Keywords: Leydig Cell Tumor, Male, Orchiectomy, Precocious Puberty, Testicular Neoplasms.

\section{Introduction}

Leydig cell tumor is a sex cord stromal tumor of the testis with low incidence. It usually manifests in preadolescent boys or in older males. It is a nongerm cell tumor of the testis and is included in the group of specialized gonadal stromal neoplasms. The usual clinical presentation is that of a testicular mass in a pre-adolescent boy with features of isosexual precocious puberty. In this article we share our experience of a 3 year old boy who was worked up extensively for iso-sexual precocious puberty. A right testicular mass was detected later which prompted a scrotal ultrasound. This revealed a testicular tumor prompting the family to seek surgical opinion.

\section{Case Report}

Three year old boy presented to a pediatrician with a history of gradual enlargement of penis followed by pubic hair growth. He also developed facial hair growth, voice change and increase in appetite.
There was no family history of precocious puberty. He was referred to a pediatric endocrinologist for workup. Six months later the family noticed a right testicular enlargement. This prompted an ultrasound of the scrotum which showed a right testicular tumor. Patient's family self-referred to us for further treatment.

On examination the boy had facial hair growth, enlarged penis, masculine voice and increased appetite. His pubic hair, penis and scrotum were Tanner stage 4 [Fig.1]. He had no axillary hair. His right testis was uniformly enlarged and non-tender. His bone age was 11 years as showed by an X-ray of his non-dominant hand. His height was $115 \mathrm{cms}$ (above 95 percentile for his age) and his weight was 24 kilograms (above 95 percentile for his age).

Blood investigations revealed an elevated serum testosterone level of $9.2 \mathrm{nmol} / \mathrm{L}$ (normal values for pre-pubertal male less than $1 \mathrm{nmol} / \mathrm{L}$ ) and suppressed serum LH (0.4I U/L) and FSH 
(0.1I U/L) (normal values upto $4 \mathrm{IU} / \mathrm{L}$ for both). Scrotal ultrasound revealed a hypo-echoic lesion in the right testes suspicious of a tumor. A hormonally active testicular tumor was suspected and a right high inguinal orchidectomy was done. Cut section showed a dark golden brownish tumor occupying most of the right testis [Fig.2]. Histopathology revealed a Leydig cell tumor. Follow up hormonal studies after 2 months revealed a serum testosterone of $0.025 \mathrm{nmol} / \mathrm{L}$ and LH and FSH of $1 \mathrm{IU} / \mathrm{L}$ (normal pre-pubertal values).

\section{Discussion}

Leydig cell tumors are most common amongst sex cord-stromal tumors. They comprise only $1-3 \%$ of all testicular tumors [1] and usually elaborate hormones particularly androgens and in some cases both androgens and estrogens, and rarely corticosteroids [1,2]. They may present in children, although most cases occur between 20 and 60 years of age [3]. In children, they tend to present in boys in age group of 5 to 10 years with precocious puberty.

The precocious puberty is a peripherally driven etiology with hormone profile consisting of low levels of gonadotropins ( $\mathrm{LH}$ and FSH), and an elevated testosterone. Adults usually present with testicular swelling and gynecomastia. Clinically most of these tumors are benign. Malignant Leydig cell tumors occur in approximately $10 \%$, almost exclusively in post-pubertal males. Because small testicular masses may not be palpable, all boys with precocious puberty and an absent family history of precocious puberty should undergo testicular ultrasonography. It is also important to accurately differentiate conditions that will respond to medical management (like Leydig cell hyperplasia due to congenital adrenal hyperplasia) from Leydig cell tumors which require definitive surgical therapy [4].

Leydig cell tumor is a subtype of sex cord stromal tumors which accounts for $8 \%$ to $11 \%$ of all pediatric testicular tumors. Grossly these

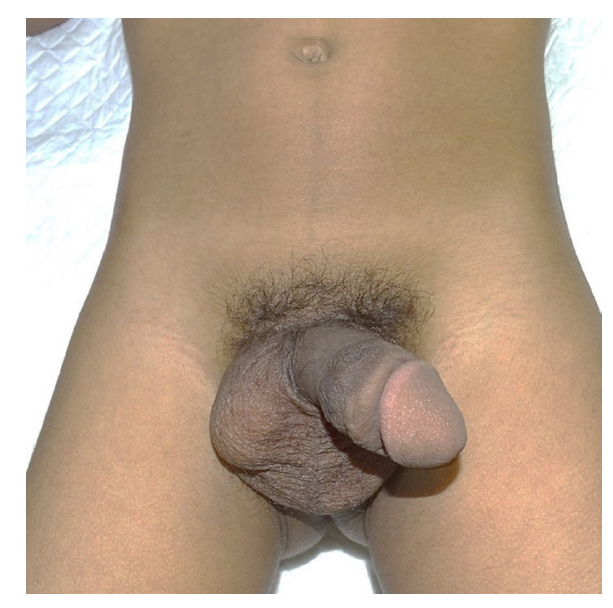

Fig.1: Shows penile enlargement and pubic hair.

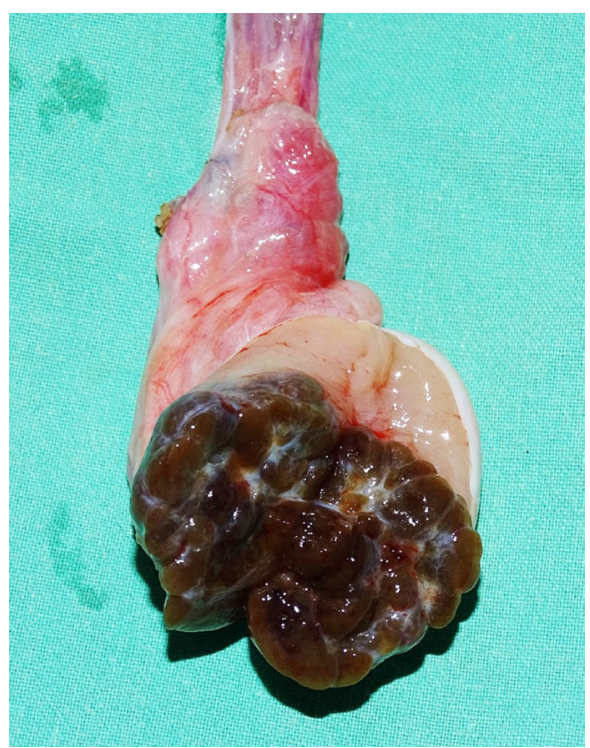

Fig.2: Cut section of right orchidectomy specimen showing characteristic golden brown colour of the tumor almost replacing the whole right testis.

neoplasms form circumscribed nodules. They have a distinctive golden brown homogeneous cut surface. Histologically, neoplastic Leydig cells resemble their normal counterparts. The cytoplasm contains frequently contains lipid granules, vacuoles, or lipofuscin pigment, and most characteristically, rod-shaped crystalloids of Reinke which occur in about $25 \%$ of the tumors [3]. Malignancy in a Leydig cell tumor is suggested by a larger size of tumor, infiltrative margins, foci of necrosis, angiolymphatic invasion, nuclear atypia, 
mitotic count $>3 / 10$ HPF, DNA aneuploidy, and increased MIB-1 activity [2].

Surgery for Leydig cell tumor consists of either testis sparing surgery or inguinal orchidectomy. Since the diagnosis can be established pre-operatively with hormone studies and the universal benign nature of this tumor in pre-pubertal boys, some authors believe that these tumors are best treated with testis sparing enucleation [5]. Our patient developed symptoms of iso-sexual precocious puberty at the age of three, much younger than the usual reported age range. He was being worked up extensively for isosexual precocious puberty for several months by a pediatrician and pediatric endocrinologist.

Parents noticed right testicular enlargement and a scrotal ultrasound showed a right testicular mass. Based on the typical clinical presentation and hormonal levels, we suspected Leydig cell tumor. Since the ultrasound showed that the tumor was occupying almost whole of the right testis we proceded with right inguinal orchiectomy.

\section{Conclusion}

Children with iso-sexual precocious puberty usually present to pediatricians and endocrinologists. Hormone secreting testicular tumors in boys usually present with features of iso-sexual precocity. This should always be considered high in differential diagnosis. Work up would include a testicular examination as well as a scrotal ultrasound. Surgical management consists of either testis sparing surgery or an inguinal orchidectomy. Strong suspicion is the key to early surgical referral and management.

Contributors: KBP, DHK: manuscript writing, patient management; SVP: manuscript editing, patient management; SSJ: critical inputs into the manuscript, patient management. KBP will act as guarantor. All authors approved the final version of the manuscript.

Funding: None; Competing interests: None stated.

\section{References}

1. Kim I, Young R, Scully R. Leydig cell Tumors of the testis. A clinicopathological analysis of 40 cases and review of the literature. Am J Surg Path. 1985;9:177192.

2. Cheville JC, Sebo TJ, Lager DJ, Bostwick DG, Farrow GM. Leydig cell tumor of the testis: a clinicopathologic, DNA content and MIB-1 comparison of nonmetastasizing and metastasizing tumors. Am J Surg Path. 1998;22:1361-1367.

3. Epstein JI. Testicular tumors. In: Kumar V, Abbas AK, Fausto N, Aster JC (ed). Robbins and Cotran Pathologic Basis of Disease. $8^{\text {th }}$ ed. Philadelphia: Saunders Elsevier; 2010. pp.1164.

4. Rich, MA, Keating, MA. Leydig cell tumors and tumors associated with congenital adrenal hyperplasia. Urol Clin of North Am. 2000;27:519-528.

5. Henderson CG, Ahmed AA, Sesterhenn I, Belman AB, Rushton HG. Enucleation for prepubertal Leydig cell tumor. J Urol. 2006;176:703-705. 